\title{
Molecular cloning and expression analysis of a matrix Gla protein gene in the spinyhead croaker, Collichthys lucidus
}

W. Song, M.D. Zhao, K.J. Jiang, F.Y. Zhang, M. Zhao, Y.Y. Meng and

L.B. Ma

East China Sea Fisheries Research Institute,

Chinese Academy of Fishery Sciences, Shanghai, China

Corresponding author: L.B. Ma

E-mail: swift83@sina.com

Genet. Mol. Res. 15 (4): gmr15049028

Received July 25, 2016

Accepted September 12, 2016

Published November 3, 2016

DOI http://dx.doi.org/10.4238/gmr15049028

Copyright $(C 2016$ The Authors. This is an open-access article distributed under the terms of the Creative Commons Attribution ShareAlike (CC BY-SA) 4.0 License.

\begin{abstract}
The matrix Gla (gamma-carboxyglutamic acid-rich) protein (MGP), a vitamin K-dependent and Gla-containing protein, is a calcification inhibitor that mainly functions in tissue calcification and mineralization. In this study, we obtained the complete cDNA sequence of $M G P$ from the spinyhead croaker (Collichthys lucidus), which we named $C l-M G P$. Cl-MGP was 923 bp long with a 384-bp open reading fragment that encoded 127 amino acids. The predicted MGP protein sequence contained a 19-residue hydrophobic signal peptide, suggesting that it possesses secretory characteristics. The Gla domain and the invariant unit ErraEtCedyspC, which has been identified in all known vitamin K-dependent vertebrate proteins, were highly conserved in Cl-MGP, suggesting that it uses the same mechanism to function as the known proteins. An alignment analysis revealed that Cl-MGP had the highest identity with Larimichthys crocea (93\%), which had
\end{abstract}

Genetics and Molecular Research 15 (4): gmr15049028 
lost five amino acid residues in the C-terminal. A quantitative realtime polymerase chain reaction revealed that $C l-M G P$ expression was highest in the gill, followed by the cholecyst and spleen, with almost no expression in the blood, muscle, or testes. The high $\mathrm{Cl}-\mathrm{MGP}$ expression in the gill is similar to that observed in other fish species, but the relatively high expression found in the cholecyst and spleen is not seen in all species. Future studies should investigate the tissue distributions of both mRNA and proteins in different species, in order to understand the function and evolution of MGP in different species.

Key words: Matrix Gla protein; Collichthys lucidus; Gene clone; mRNA expression

\section{INTRODUCTION}

Calcification of the extracellular matrix can be physiological or pathological. The inappropriate calcification of some soft tissues, such as arteries and cartilage, could be lethal. Matrix Gla (gamma-carboxyglutamic acid-rich) protein (MGP) is a vitamin K-dependent and Gla-containing protein that was first discovered in the bovine bone, and was the first artery and cartilage calcification inhibitor found. MGP-deficient mice die within two months as a result of arterial calcification, which leads to rupture of the blood vessels (Price et al., 1983; Luo et al., 1997). Furthermore, it has been demonstrated that MGP is associated with carotid stenosis, and the serum MGP level could be used as both an arterial calcification and carotid atherosclerosis index (Dana et al., 2011). A comparison of MGP expression in aortic valve interstitial cells (AVICs) in carotid stenosis patients and healthy controls revealed that MGP expression was significantly lower in the patients' AVICs, suggesting that an important anti-calcification defense mechanism is deficient in calcified aortic valves, which might be an important cause of carotid stenosis (Venardos et al., 2015). It has also been found that MGP suppresses angiogenic sprouting from the mouse aorta by coordinating both the Notch and bone morphogenetic protein signaling pathways; therefore, it plays an important role in microvasculature (Sharma and Albig, 2013). Two vitamin K-dependent post-translational modifications, gamma-glutamyl carboxylation and serine phosphorylation, are necessary for the activation of MGP, and high levels of plasma desphospho-uncarboxylated MGP are a proxy for vitamin K deficiency (Epstein, 2016). Polymorphisms in the MGP gene are associated with a genetic susceptibility to kidney stones (Gao et al., 2007). All of these findings have underlined the importance of MGP in medical research; however, research on Xenopus laevis has revealed that non-mammalian model systems also have important roles to play in the elucidation of the complex regulation of $M G P$ (Conceição et al., 2005).

$M G P$ has been obtained from many fish species, including Sparus aurata (Pinto et al., 2003), Argyrosomus regius (Simes et al., 2003), Danio rerio and Solea senegalensis (Gavaia et al., 2006), Scophthalmus maximus (Roberto et al., 2009), and Acipenser naccarii (Viegas et al., 2013). It is expressed in cartilage, heart, and kidney tissues in A. regius, which is in general agreement with $M G P$ in mammals. However, the MGP protein only accumulates in calcified cartilage (Simes et al., 2003). A study on zebrafish and sole revealed that the distribution of MGP in these species is similar to that in mammals, but in contrast with A. regius, the protein accumulates in the extracellular matrix of the bone, cartilage, and tooth cementum (Simes

Genetics and Molecular Research 15 (4): gmr15049028 
et al., 2003). These findings suggest that MGP regulation might differ between different fish species. Moreover, a study on $S$. aurata revealed that retinoic acid could bind to the MGP promoter and can downregulate $M G P$ expression, providing additional evidence for the utility of non-mammalian model systems (Conceição et al., 2008).

The spinyhead croaker, Collichthys lucidus (Perciformes, Sciaenidae, Collichthys), is a commercially important near-shore species that is widely distributed in the South and East China Seas (Cheng et al., 2012). Because of its population decline, previous studies on $C$. lucidus have mainly focused on population genetics and breeding programs (Zhao et al., 2015), and only a few genes in this species have been reported (Sang et al., 2015a,b; Song et al., 2016a,b). The aim of the present study was to characterize the $\mathrm{Cl}$ $M G P$ sequence and analyze its expression patterns in different tissues, in order to provide basic information and lay a preliminary foundation for the investigation of gene function in this species, and its aquaculture.

\section{MATERIAL AND METHODS}

\section{Ethics statement}

All of the animal experiments in this study were conducted in accordance with the relevant national and international guidelines. Our project was approved by the East China Sea Fisheries Research Institute. In China, catching C. lucidus in the sea does not require specific permits. Our study did not involve endangered or protected species.

\section{Construction of a cDNA library and cloning MGP cDNA from $C$. lucidus}

Healthy fish weighing $35 \pm 5 \mathrm{~g}$ (means $\pm \mathrm{SD}$ ) were caught in the East China Sea near Shanghai, China. Tissues weighing $200 \pm 50 \mathrm{mg}$ (means \pm SEM) for RNA extraction were obtained by vivisection on fishing boats, which were then stored in a $1.5-\mathrm{mL}$ RNA fixer (Bioteke Corporation, Beijing) at $-20^{\circ} \mathrm{C}$. Three replicates (fish) were dissected. Total RNA was isolated from the liver, brain, testes, cholecyst, spleen, kidney, gill, heart, muscle, and blood using TRIpure Reagent (Aidlab, Beijing) following the manufacturer protocol. The RNA concentrations and quality were assessed using spectrophotometry (DU800 Nucleic Acid/Protein Analyzer, Beckman Coulter) and agarose gel electrophoresis (Universal Hood II, Bio-Rad Laboratories Inc., Hercules, CA, USA). The RNA was then stored at $-80^{\circ} \mathrm{C}$ until use.

A cDNA library was successfully constructed using a SMART ${ }^{\text {TM }}$ cDNA Library Construction Kit (TaKaRa, Dalian), which was followed by transformation, screening, and random sequencing. All of the expressed sequence tags were subjected to a BLAST analysis.

A cDNA sequence comprising the MGP domain was obtained and subjected to further investigation. A 3' rapid amplification of cDNA ends (RACE) was conducted following the manufacturer protocol, using a 3'-full RACE Core Set (TaKaRa) to obtain the full-length cDNA sequence. Cl-MGP outer (5'-CAGGAGAAACATACGCACAG-3', as the 3'-RACE outer primer) and $C l-M G P$ inner [5'-CCCAGGAGGAACGGCAACA-3', as the nest polymerase chain reaction (PCR) primer] were designed and used for 3'-RACE. A PCR was conducted following the manufacturer instructions. The PCR products were checked on $1.0 \%$ agarose gel and purified using an Agarose Gel DNA Purification Kit V. 2. 0. (TaKaRa), and then cloned into a pMD19-T vector (TaKaRa) for sequencing.

Genetics and Molecular Research 15 (4): gmr15049028 


\section{Bioinformatic analysis}

The general features of $\mathrm{Cl}-\mathrm{MGP}$ full-length cDNA were investigated using Vector NTI Advance ${ }^{\circledR} 11.5$, and the protein sequence was deduced and compared with other MGPs using the National Center for Biotechnology Information's (NCBI) open reading frame (ORF) Finder (https://www.ncbi.nlm.nih.gov/orffinder/). Biochemical features of the deduced protein were calculated using the DNASTAR software (http://www.dnastar. com/). Amino acid sequences from various species were downloaded from GenBank for further analysis. A neighbor-joining phylogenetic tree was constructed using the MEGA software version 5.0 (Tamura et al., 2011), and the confidence level was obtained using 1000 bootstraps.

\section{Tissue distribution analysis of $C l-M G P$ mRNA in adult $C$. lucidus}

Liver, brain, testes, cholecyst, spleen, kidney, gill, heart, muscle, and blood tissues were obtained using the same method as described above, from which total RNA (about $1 \mathrm{mg}$ ) was extracted and reverse transcribed using a Quantitative Real-Time PCR (qRT-PCR) Kit (Toyobo, Japan) for the first cDNA strand. The products were diluted $10 \mathrm{X}$ and stored at $-20^{\circ} \mathrm{C}$ until qRT-PCR analysis.

The qRT-PCR assay was performed using a detection system (StepOnePlus ${ }^{\mathrm{TM}}$, Applied Biosystems). $C l-M G P$ transcript expression profiles were detected by qRT-PCR using a pair of Cl-MGP-specific primers (Cl-MGP-RTF, 5'-CCAGGAGGAACGGCAACA-3'; Cl-MGP-RTR, 5'-GAAGCCGCAGCCTTTGTTCTT-3'). The 18S rRNA was the internal control gene, and the primers were the same as previously reported (Song et al., 2016a). Cl-MGP expression levels were calculated by the relative standard curve method. Amplifications were performed on a 96well plate with a $20-\mu \mathrm{L}$ reaction volume, and each sample was repeated three times. Details of the reaction system and procedure have been published previously (Song et al., 2016a,b).

\section{RESULTS AND DISCUSSION}

\section{Determination of $\mathrm{Cl}$-MGP cDNA}

The full-length $C l-M G P$ cDNA was obtained and submitted to GenBank with the accession No. KX002213. The complete sequence was 923 bp in length, and contained a 384-bp ORF (that encoded a protein of 127 amino acids), a 132-bp 5'-untranslated region (UTR), and a 407-bp 3'-UTR. A typical polyadenylation signal (AATAAA) was located $15 \mathrm{bp}$ upstream of the poly (A) + tail (Figure 1). The predicted molecular weight was $14.744 \mathrm{kDa}$, with an isoelectric point of 9.69. A 19-residue hydrophobic signal peptide was found on the N-terminal, suggesting that it possesses secretory characteristics. Gla and the invariant unit ErraEtCedyspC (EXXXEXCXXXXXC), which has been identified in all known vitamin $\mathrm{K}$-dependent vertebrate proteins, are important for the recognition of the carboxylase (Price et al., 1987). In a study on human vascular smooth muscle cell monolayers, Schurgers et al. (2007) used a vitamin K antagonist to show that the $\gamma$-glutamyl carboxylation and serine phosphorylation of MGP is essential for its inhibition. The putative ErraEtC motif was conserved, suggesting that $C l-M G P$ might be activated by the same mechanism.

Genetics and Molecular Research 15 (4): gmr15049028 


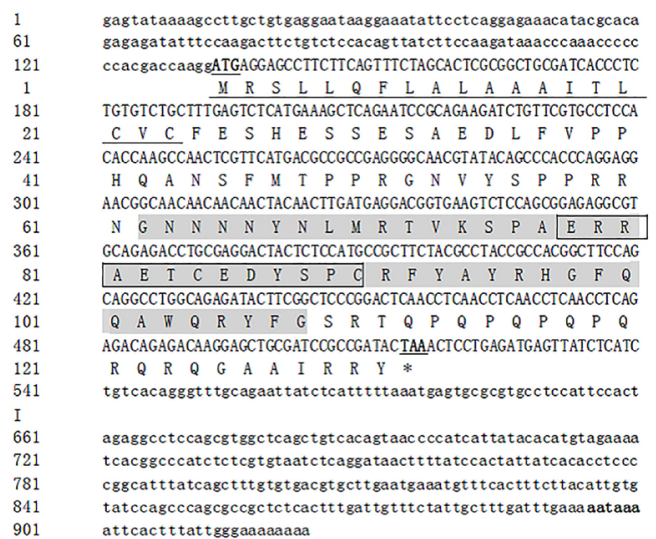

Figure 1. Nucleotide sequence of cDNA and predicted amino acid sequences of Collichthys lucidus $\mathrm{MGP}$ (Cl$M G P$ ). The amino acid sequences of $\mathrm{Cl}-\mathrm{MGP}$ are translated and signal peptides are underlined. Start codons (ATG) and stop codons (TAA) are bolded and underlined, and the polyadenylation signal (AATAAA) is bolded. The Gla domain is shaded, and the invariant unit (EXXXEXCXXXXXC) in this domain is boxed.

Twenty-six amino acid sequences from various species were obtained using "MGP" as the keyword in the NCBI protein database (http://www.ncbi.nlm.nih.gov/guide/ proteins/\#databases_). Twelve of them were aligned with Cl-MGP using DNAMAN (Figure 2); MGP in Larimichthys crocea had the highest identity (93\%) with Cl-MGP, followed by those in Anoplopoma fimbria, Dicentrarchus labrax, and Stegastes partitus (80\%). The MGP in D. rerio had the lowest identity with Cl-MGP (44\%). The putative signal peptide was relatively highly conserved, except in $D$. rerio, and the MGP in D. rerio had the lowest identity with that in the other species. The MGP in S. senegalensis is first detected at 8 days post-fertilization in the cartilaginous otic capsules, but not in the otoliths (Gavaia et al., 2006); the function of MGP in D. rerio should be further investigated.
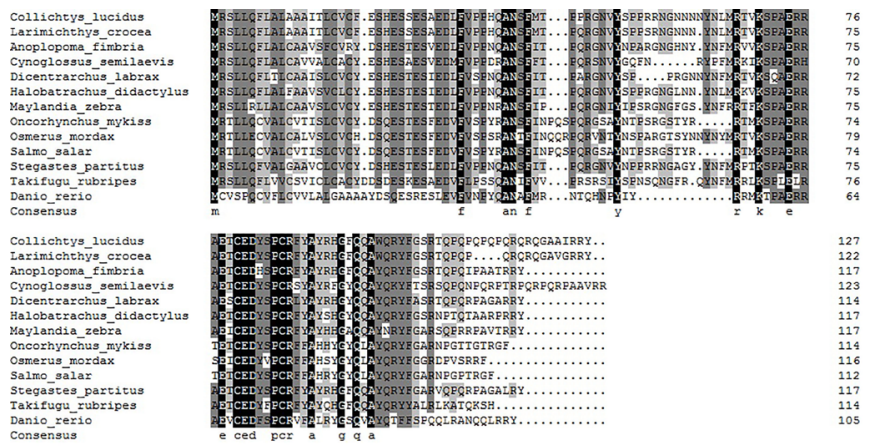

Figure 2. ClustalW alignment and comparison of the amino acid sequences deduced from Collichthys lucidus MGP cDNA with similar MGP protein sequences. Similarities higher than $50 \%$ are labeled with different colors. The amino acid sequence deduced from C. lucidus is marked as Cl-MGP. Similar proteins predicted and obtained from GenBank were as follows: Larimichthys crocea (XP_010744668.1); Anoplopoma fimbria (ACQ59054.1); Cynoglossus semilaevis (XP_008328565.1); Dicentrarchus labrax (AAY17286.1); Halobatrachus didactylus (AAP04489.1); Maylandia zebra (XP 004563073.1); Oncorhynchus mykiss (AAO64979.1); Osmerus mordax (ACO09134.1); Salmo salar (ACI69324.1); Stegastes partitus (XP_008282770.1); Takifugu rubripes (AAM66790.1); and Danio rerio (NP_991203.1).

Genetics and Molecular Research 15 (4): gmr15049028 
Interestingly, an Asn (residue 61) and Gln-Pro-Gln-Pro sequence (residues 112-115) were lost in L. crocea. As C. lucidus and L. crocea are closely related, it would be interesting to investigate the functions of these residues.

The phylogenetic tree is presented in Figure 3, and includes all 27 aligned amino acid sequences. According to the tree, all of the MGPs can be divided into two branches, one for fish species and another for mammals and birds. Unsurprisingly, Cl-MGP has the closest relationship with L. crocea. MGP evolution in birds and mammals should be further investigated.

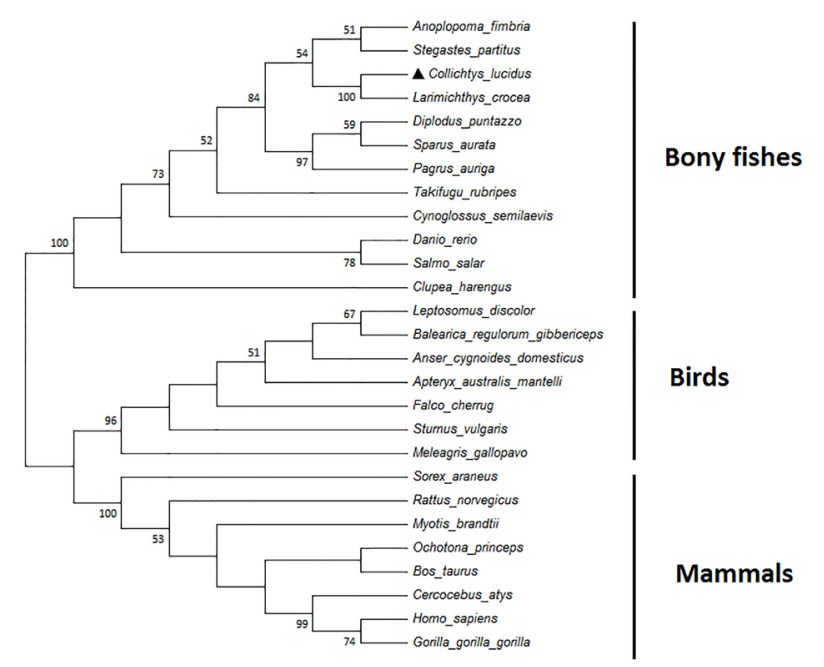

Figure 3. Phylogenetic tree based on MGP amino acid sequences. The following protein sequences were obtained from GenBank: Anoplopoma fimbria (ACQ59054.1); Stegastes partitus (XP_008282770.1); Larimichthys crocea (XP 010744668.1); Diplodus puntazzo (AAY17283.1); Sparus aurata (AAL55445.1); Pagrus auriga (AAY17285.1); Takifugu rubripes (AAM66790.1); Cynoglossus semilaevis (XP 008328565.1); Danio rerio (NP 991203.1); Salmo salar (ACI69324.1); Clupea harengus (XP 012681059.1); Leptosomus discolor (XP_009945519.1); Balearica regulorum gibbericeps (XP_010298047.1); Anser cygnoides domesticus (XP_013051962.1); Apteryx australis mantelli (XP_013802723.1); Falco cherrug (XP_005441377.1); Sturnus vulgaris (XP 014747945.1); Meleagris gallopavo (X̄ norvegicus (AAH86394.1); Myotis brandtii (XP_005866847.1); Ochotona princeps (XP_004592642.1); Bos taurus (CAA30288.1); Cercocebus atys (XP_011913872.1); Homo sapiens (NP_001177768.1); and Gorilla gorilla gorilla (XP_004052839.1).

\section{Relative $\mathrm{Cl}$-MGP expression in different tissues}

Cl-MGP was most highly expressed in the gill, followed by the cholecyst and spleen. The kidney and liver had low expression levels, and almost no expression could be detected in the heart, blood, muscle, testes, or brain (Figure 4). The high gill expression is similar to that found in S. maximus (Roberto et al., 2009), S. aurata (Pinto et al., 2003), and A. naccarii (Viegas et al., 2013), but unlike $C$. lucidus, $A$. naccarii has very low $M G P$ expression in the spleen (Viegas et al., 2013). In A. regius, $M G P$ expression is highest in the heart, branchial arches, and vertebrae (Simes et al., 2003). Future studies should investigate the tissue distributions of both mRNA and proteins in different species, in order to understand the function and evolution of MGP in different species. 


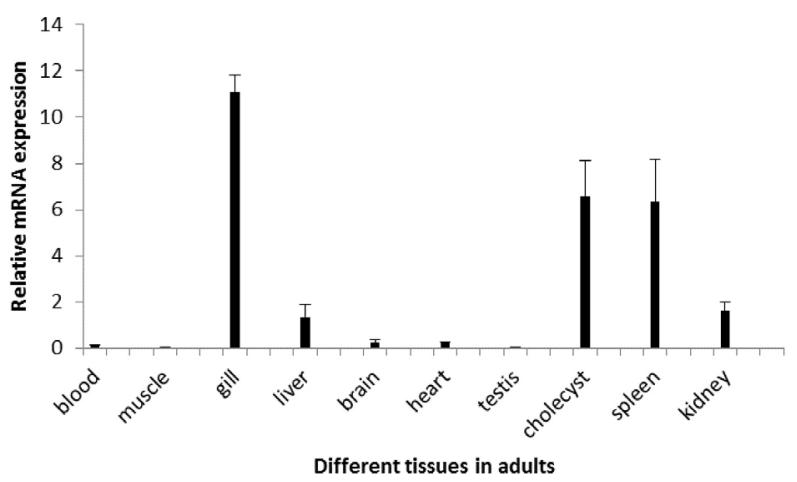

Figure 4. $\mathrm{Cl}-\mathrm{MGP}$ expression profiles in different tissues. The amount of $\mathrm{Cl}-\mathrm{MGP}$ mRNA was normalized to the $18 S r R N A$ transcript level. The y-axis represents the ratio of the relative expression levels of $C l-M G P$ to $18 S r R N A$.

\section{Conflicts of interest}

The authors declare no conflict of interest.

\section{ACKNOWLEDGMENTS}

Research supported by the Basic Research Fund for State-Level Nonprofit Research Institutes of East China Sea Fishery Research Institute (ECSFRI) and the Chinese Academic of Fishery Science (CAFS) (\#Dong2015M08).

\section{REFERENCES}

Cheng J, Ma GQ, Miao ZQ, Shui BN, et al. (2012). Complete mitochondrial genome sequence of the spinyhead croaker Collichthys lucidus (Perciformes, Sciaenidae) with phylogenetic considerations. Mol. Biol. Rep. 39: 4249-4259. http://dx.doi.org/10.1007/s11033-011-1211-6

Conceição N, Silva AC, Fidalgo J, Belo JA, et al. (2005). Identification of alternative promoter usage for the matrix Gla protein gene. Evidence for differential expression during early development in Xenopus laevis. FEBS J. 272: 15011510. http://dx.doi.org/10.1111/j.1742-4658.2005.04590.x

Conceição N, Laizé V, Simões B, Pombinho AR, et al. (2008). Retinoic acid is a negative regulator of matrix Gla protein gene expression in teleost fish Sparus aurata. Biochim. Biophys. Acta 1779: 28-39. http://dx.doi.org/10.1016/j. bbagrm.2007.11.003

Dana P, Adela ST, Elena G, Gyorgy B, et al. (2011). The relationship between matrix GLA protein (MGP) and carotid stenosis. Rev. Rom. Med. Lab. 19: 169-175.

Epstein M (2016). Matrix Gla-protein (MGP) not only inhibits calcification in large arteries but also may be renoprotective: connecting the dots. EBioMedicine 4: 16-17.http://dx.doi.org/10.1016/j.ebiom.2016.01.026

Gao B, Yasui T, Itoh Y, Tozawa K, et al. (2007). A polymorphism of matrix Gla protein gene is associated with kidney stones. J. Urol. 177: 2361-2365.http://dx.doi.org/10.1016/j.juro.2007.01.118

Gavaia PJ, Simes DC, Ortiz-Delgado JB, Viegas CS, et al. (2006). Osteocalcin and matrix Gla protein in zebrafish (Danio rerio) and Senegal sole (Solea senegalensis): comparative gene and protein expression during larval development through adulthood. Gene Expr. Patterns 6: 637-652.http://dx.doi.org/10.1016/j.modgep.2005.11.010

Luo G, Ducy P, McKee MD, Pinero GJ, et al. (1997). Spontaneous calcification of arteries and cartilage in mice lacking matrix GLA protein. Nature 386: 78-81.http://dx.doi.org/10.1038/386078a0

Pinto JP, Conceição N, Gavaia PJ and Cancela ML (2003). Matrix Gla protein gene expression and protein accumulation colocalize with cartilage distribution during development of the teleost fish Sparus aurata. Bone 32: 201-210. http:// dx.doi.org/10.1016/S8756-3282(02)00981-X

Genetics and Molecular Research 15 (4): gmr15049028 
Price PA, Urist MR and Otawara Y (1983). Matrix Gla protein, a new gamma-carboxyglutamic acid-containing protein which is associated with the organic matrix of bone. Biochem. Biophys. Res. Commun. 117: 765-771. http://dx.doi. org/10.1016/0006-291X(83)91663-7

Price PA, Fraser JD and Metz-Virca G (1987). Molecular cloning of matrix Gla protein: implications for substrate recognition by the vitamin K-dependent gamma-carboxylase. Proc. Natl. Acad. Sci. USA 84: 8335-8339. http:// dx.doi.org/10.1073/pnas.84.23.8335

Roberto VP, Cavaco S, Viegas CSB, Simes DC, et al. (2009). Matrix Gla protein in turbot (Scophthalmus maximus): gene expression analysis and identification of sites of protein accumulation. Aquaculture 294: 202-211. http://dx.doi. org/10.1016/j.aquaculture.2009.06.020

Sang C, Lin Y, Jiang K, Zhang F, et al. (2015a). Molecular cloning and mRNA expression of a hepcidin gene from the spinyhead croaker, Collichthys lucidus. Genet. Mol. Res. 14: 16050-16059. http://dx.doi.org/10.4238/2015. December.7.18

Sang C, Lin Y, Jiang K, Zhang F, et al. (2015b). Molecular cloning and expression analysis of MyD88 in spiny head croaker, Collichthys lucidus. Genet. Mol. Res. 14: 4666-4676.http://dx.doi.org/10.4238/2015.May.4.26

Schurgers LJ, Spronk HMH, Skepper JN, Hackeng TM, et al. (2007). Post-translational modifications regulate matrix Gla protein function: importance for inhibition of vascular smooth muscle cell calcification. J. Thromb. Haemost. 5: 2503-2511.http://dx.doi.org/10.1111/j.1538-7836.2007.02758.x

Sharma B and Albig AR (2013). Matrix Gla protein reinforces angiogenic resolution. Microvasc. Res. 85: 24-33. http:// dx.doi.org/10.1016/j.mvr.2012.10.005

Simes DC, Williamson MK, Ortiz-Delgado JB, Viegas CSB, et al. (2003). Purification of matrix Gla protein from a marine teleost fish, Argyrosomus regius: calcified cartilage and not bone as the primary site of MGP accumulation in fish. $J$. Bone Miner. Res. 18: 244-259.http://dx.doi.org/10.1359/jbmr.2003.18.2.244

Song W, Jiang KJ, Zhang FY, Zhao M, et al. (2016a). Molecular cloning and gene expression analysis of cystatin C-like proteins in spinyhead croaker Collichthys lucidus. Genet. Mol. Res. 15: gmr.15017417. http://dx.doi.org/10.4238/ gmr.15017417.

Song W, Jiang KJ, Zhang FY, Wang J, et al. (2016b). Characterization, molecular cloning, and expression analysis of Ecsit in the spinyhead croaker, Collichthys lucidus. Genet. Mol. Res. 15: gmr.15017193. http://dx.doi.org/10.4238/ gmr.15017193.

Tamura K, Peterson D, Peterson N, Stecher G, et al. (2011). MEGA5: molecular evolutionary genetics analysis using maximum likelihood, evolutionary distance, and maximum parsimony methods. Mol. Biol. Evol. 28: 2731-2739. http://dx.doi.org/10.1093/molbev/msr121

Venardos N, Bennett D, Weyant MJ, Reece TB, et al. (2015). Matrix Gla protein regulates calcification of the aortic valve. J. Surg. Res. 199: 1-6. http://dx.doi.org/10.1016/j.jss.2015.04.076

Viegas CSB, Simes DC, Williamson MK, Cavaco S, et al. (2013). Sturgeon osteocalcin shares structural features with matrix Gla protein: evolutionary relationship and functional implications. J. Biol. Chem. 288: 27801-27811. http:// dx.doi.org/10.1074/jbc.M113.450213

Zhao M, Song W, Ma CY, Zhang FY, et al. (2015). Population genetic structure of Collichthys lucidus based on the mitochondrial cytochrome oxidase subunit I sequence. J. Fish Sci. Chin 22: 233-242.

Genetics and Molecular Research 15 (4): gmr15049028 